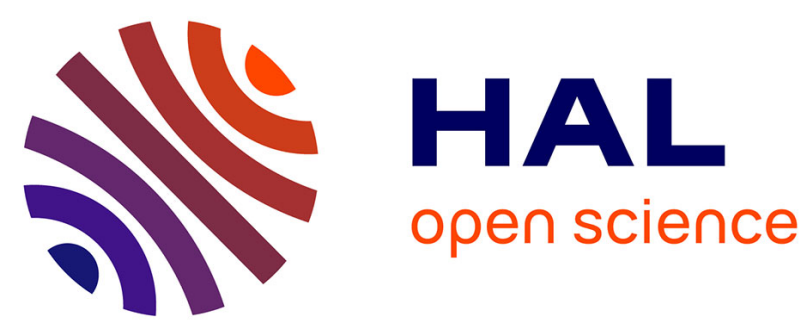

\title{
In vitro antimicrobial activity of nitrofurantoin against Escherichia coli and Staphylococcus pseudintermedius isolated from dogs and cats
}

Marit Maaland, Luca Guardabassi

\section{- To cite this version:}

Marit Maaland, Luca Guardabassi. In vitro antimicrobial activity of nitrofurantoin against Escherichia coli and Staphylococcus pseudintermedius isolated from dogs and cats. Veterinary Microbiology, 2011, 151 (3-4), pp.396. 10.1016/j.vetmic.2011.03.009 . hal-00717092

\section{HAL Id: hal-00717092 \\ https://hal.science/hal-00717092}

Submitted on 12 Jul 2012

HAL is a multi-disciplinary open access archive for the deposit and dissemination of scientific research documents, whether they are published or not. The documents may come from teaching and research institutions in France or abroad, or from public or private research centers.
L'archive ouverte pluridisciplinaire HAL, est destinée au dépôt et à la diffusion de documents scientifiques de niveau recherche, publiés ou non, émanant des établissements d'enseignement et de recherche français ou étrangers, des laboratoires publics ou privés. 


\section{Accepted Manuscript}

Title: In vitro antimicrobial activity of nitrofurantoin against Escherichia coli and Staphylococcus pseudintermedius isolated from dogs and cats

Authors: Marit Maaland, Luca Guardabassi

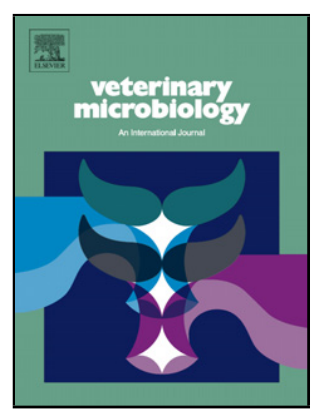

PII: S0378-1135(11)00147-7

DOI: doi:10.1016/j.vetmic.2011.03.009

Reference: VETMIC 5232

To appear in: $\quad$ VETMIC

Received date: $\quad 14-12-2010$

Revised date: 2-3-2011

Accepted date: $\quad$ 10-3-2011

Please cite this article as: Maaland, M., Guardabassi, L., In vitro antimicrobial activity of nitrofurantoin against Escherichia coli and Staphylococcus pseudintermedius isolated from dogs and cats, Veterinary Microbiology (2010), doi:10.1016/j.vetmic.2011.03.009

This is a PDF file of an unedited manuscript that has been accepted for publication. As a service to our customers we are providing this early version of the manuscript. The manuscript will undergo copyediting, typesetting, and review of the resulting proof before it is published in its final form. Please note that during the production process errors may be discovered which could affect the content, and all legal disclaimers that apply to the journal pertain. 
$1 \quad$ In vitro antimicrobial activity of nitrofurantoin against Escherichia coli and Staphylococcus

2 pseudintermedius isolated from dogs and cats

3

4 Marit Maaland and Luca Guardabassi*

5 Department of Veterinary Disease Biology, Faculty of Life Sciences, University of Copenhagen,

$6 \quad$ Frederiksberg $C$, Denmark

7

8 Running title: Nitrofurantoin susceptibility in small animal urinary tract pathogens

10 *Corresponding author: Luca Guardabassi, Department of Veterinary Disease Biology, Faculty

11 of Life Sciences, University of Copenhagen, Stigbøjlen 4, Frederiksberg C. 1870, Denmark; Tel:

12 +45 35332745; Fax: +45 35332757; e-mail: 1 g@life.ku.dk

13

14 Keywords: veterinary medicine, cystitis, antibiotic resistance, rational antibiotic use 


\section{Abstract}

16 Minimum inhibitory concentrations (MIC) of nitrofurantoin were determined by agar dilution in

17269 canine and feline isolates of Escherichia coli and Staphylococcus pseudintermedius, two of

18 the most common bacterial species associated with urinary tract infection (UTI) in small animals.

19 The MIC90 for E. coli and S. pseudintermedius were 32 and $16 \mu \mathrm{g} / \mathrm{ml}$, respectively. All isolates,

20 including multidrug-resistant strains of known genetic background, displayed MICs below the

21 drug concentrations reported in canine urine following oral administration of nitrofurantoin.

22 Preliminary data on mutant prevention concentration (MPC) and many years of nitrofurantoin

23 usage in human medicine suggest that emergence of resistant mutants during treatment is not a

24 critical issue for this drug. The study provides species-specific data on nitrofurantoin MIC

25 distribution that can be used for setting dog- and cat-specific breakpoints. Although

26 nitrofurantoin is not an appropriate first-line agent for empirical treatment of canine UTI due to

27 toxicity and poor pharmacokinetic properties, it may be indicated for treatment of UTI caused by

28 multidrug-resistant bacteria, which are otherwise difficult to treat using conventional veterinary

29 antimicrobial agents. 


\section{Introduction}

31 Urinary tract infection (UTI) is one of the most commonly diagnosed infectious diseases in small

32 animal practice. The bacterial pathogens most frequently associated with UTI in dogs are

33 Escherichia coli, staphylococci, Proteus, Klebsiella, enterococci and streptococci (Ling et al.,

34 2001). E. coli has been reported to account for $33-51 \%$ of all cases of canine UTI, while

35 staphylococci, mainly Staphylococcus pseudintermedius, are isolated in $12-20 \%$ of all cases

36 (Ball et al., 2008; Ling et al., 2001). Beta-lactam antibiotics such as amoxicillin (alone or in

37 combination with clavulanic acid) and cephalosporins are generally regarded as first line agents.

38 However, multidrug-resistant bacteria recently emerged in small animals, namely methicillin-

39 resistant S. pseudintermedius (MRSP) (El Zubeir et al., 2007; Kadlec et al. 2010; Loeffler et al.,

40 2007; Perreten et al., 2010; Ruscher et al., 2009) and extended-spectrum beta-lactamase (ESBL)-

41 producing E. coli (Carattoli et al., 2005; Ogeer-Gyles et al., 2006; Sanchez et al., 2002; Shaheen

42 et al., 2010; Warren et al., 2001), are per definition resistant to beta-lactams and often

43 additionally resistant to alternative drugs for treatment of UTI.

44 Nitrofurantoin is a synthetic nitrofuran that reaches very high concentrations in urine. This drug

45 has been used for the treatment of uncomplicated UTIs in humans for more than fifty years

46 (Hooper, 2010). In small animal practice, the use of nitrofurantoin has been gradually abandoned

47 due to higher toxicity and lower pharmacokinetic performance in comparison to beta-lactams,

48 fluoroquinolones and trimethoprim-sulfonamides. The objective of this study was to evaluate the

49 in vitro antimicrobial activity of nitrofurantoin against E. coli and S. pseudintermedius isolates

50 from dogs and cats, including strains previously characterized genetically as ESBL-producing $E$.

51 coli and MRSP. The results were discussed on the basis of the current knowledge of the

52 pharmacokinetic properties of nitrofurantoin in dogs. 


\section{Materials and methods}

\section{Bacterial strains}

55 A total of 106 E. coli, including 6 ESBL- and 9 CMY-producing isolates, and $163 S$.

56 pseudintermedius, including 13 MRSP, were included in the study. All isolates were collected in

57 the time period 1998 to 2010, with the majority of the strains (88\%) isolated from 2005 to 2010.

58 The isolates originated from clinical specimens obtained from infected dogs $(n=240)$ or cats

59 (n=29), except 3 MRSP, 5 ESBL- and 9 CMY-producing E. coli which had been isolated from

60 healthy dogs or during necropsy. Thirteen S. pseudintermedius isolates (including 2 MRSP) and

6139 E. coli isolates (including 1 ESBL-producing strain) were isolated from urine. Nine of the 13

62 MRSP isolates had previously been typed (Perreten et al., 2010) and belonged to seven distinct

63 clonal types (ST54, ST58, ST68, ST69, ST71, ST95 and ST113).

\section{$64 \quad$ MIC testing}

65 MIC values were determined by agar dilution in accordance with the Clinical and Laboratory

66 Standards Institute (CLSI 2008). The range of concentrations tested was between 2 and 128

$67 \mu \mathrm{g} / \mathrm{ml}$. The stock solution was prepared dissolving $250 \mathrm{mg}$ nitrofurantoin (Sigma-Aldrich,

68 Germany) in $5 \mathrm{ml}$ of dimethylformamide (DMF) to yield a final concentration of $50 \mathrm{mg} / \mathrm{ml}$.

69 Mueller Hinton agar plates (Oxoid, UK) containing nitrofurantoin were stored at $4^{\circ} \mathrm{C}$ in dark

70 plastic bags, and used within 9 days after preparation. The following reference strains were used

71 for quality control: Staphylococcus aureus ATCC 29213, Enterococcus faecalis ATCC 29212,

72 Escherichia coli ATCC 25922 and Pseudomonas aeruginosa ATCC 27853.

\section{$73 \quad$ MPC testing}


74 Mutant prevention concentrations (MPCs) of nitrofurantoin were measured in two isolates of

75 each species. MPC testing was performed according to previous studies (Blondeau, 2009;

76 Hansen and Blondeau, 2005). Briefly, for each strain the bacterial content of three 5\% blood agar

77 plates displaying confluent growth was transferred to $100 \mathrm{ml}$ of Mueller-Hinton broth (Oxoid,

78 UK) using a sterile swab. Following overnight incubation, $50 \mathrm{ml}$ of overnight culture were

79 centrifugated at $5000 \mathrm{xg}$ for $30 \mathrm{~min}$, and the pellet was resuspended in $2 \mathrm{ml}$ of broth to reach a

80 cellular density of at least $10^{10} \mathrm{CFU} / \mathrm{ml}$. Mueller-Hinton plates containing nitrofurantoin were

81 inoculated using $100 \mu \mathrm{l}$ of this bacterial suspension and incubated at $37^{\circ} \mathrm{C}$. The lowest drug

82 concentration preventing growth was recorded as the MPC. Bacterial colonies and smears on

83 plates containing nitrofurantoin concentrations higher than the MIC of the wild-type strain were

84 subcultured onto agar plates containing the same drug concentration and subjected to MIC

85 determination.

\section{Results and discussion}

88 The MICs of nitrofurantoin ranged between 8 and $32 \mu \mathrm{g} / \mathrm{ml}$ in E. coli and between 4 and 16

$89 \mu \mathrm{g} / \mathrm{ml}$ in S. pseudintermedius (Table 1). The $\mathrm{MIC}_{90}$ was $32 \mu \mathrm{g} / \mathrm{ml}$ for $E$. coli and $16 \mu \mathrm{g} / \mathrm{ml}$ for $S$.

90 pseudintermedius. The $\mathrm{MIC}_{50}$ values for the two species were 16 and $8 \mu \mathrm{g} / \mathrm{ml}$, respectively. As

91 breakpoints for nitrofurantoin resistance have not yet been established for animal E. coli and $S$.

92 pseudintermedius, only human breakpoints ( $\mathrm{S} \leq 32 \mu \mathrm{g} / \mathrm{ml}, \mathrm{R} \geq 128 \mu \mathrm{g} / \mathrm{ml}$ ) (CLSI 2010) are

93 available as references for interpretation of the MIC results. According to such breakpoints none

94 of the isolates tested was resistant to nitrofurantoin. All isolates, including the multidrug-resistant

95 strains of known genetic background, displayed MICs lower than the concentration of

96 nitrofurantoin achieved in urine following oral administration to dogs. Conklin et al. (1969) 
97 reported that four hours after oral administration (4-5 $\mathrm{mg} / \mathrm{kg}$ body weight) nitrofurantoin

98 concentrations in urine are above $60 \mu \mathrm{g} / \mathrm{ml}$ for the macrocrystalline formulation and above 100

$99 \mu \mathrm{g} / \mathrm{ml}$ for the microcrystalline formulation. For both formulations, a slight increase in drug

100 concentration was observed following repeated administration (Conklin et al., 1969). No data are

101 currently available about the urinary excretion profile within four hours after administration. In

102 an absorption and disposition study of nitrofurantoin in dogs performed by Niazi et al. (1983),

103 oral administration of a $100 \mathrm{mg}$ tablet resulted in a peak plasma level ranging from 1.5 to 4.0

$104 \mu \mathrm{g} / \mathrm{ml}$, and an elimination half-life of 32 to 87 minutes, which means that the drug is rapidly

105 distributed and eliminated from plasma. If one assumes that the urinary excretion rate changes

106 according to the plasma levels, these data indicate that urinary concentrations are high shortly

107 after administration but rapidly decrease in parallel with the decrease of the plasma levels. More

108 detailed information on the excretion profiles and on the antibacterial action of the drug (i.e.

109 concentration- vs. time-dependent) are needed in order to optimize dosage regimens in small

110 animals.

111 There are several disadvantages associated with the clinical use of nitrofurantoin in small

112 animals. The drug is a known gastrointestinal irritant and may cause nausea and emesis as side-

113 effects in both dogs and cats. Due to the short plasma half-life (Niazi et al., 1983), nitrofurantoin

114 requires frequent administration (i.e. three to four times daily). Furthermore, it cannot be used for

115 treatment of UTI associated with Proteus and Pseudomonas as these organisms are generally

116 resistant to this drug (Rohrich et al., 1983). Although better alternatives than nitrofurantoin exist

117 as first-line agents for treatment of canine UTI, the results of this study combined with the

118 current knowledge of the pharmacokinetics in dogs suggest that this drug may be indicated for

119 treatment of UTI caused by ESBL-producing E. coli and MRSP. The recent spread of these 
120 multidrug-resistant bacteria in dogs and cats represents a serious therapeutic challenge for small

121 animal veterinary practitioners since such bacteria are often resistant to all the conventional

122 veterinary antimicrobial products available for treatment of UTI in small animal medicine

123 (Carattoli et al., 2005; El Zubeir et al., 2007; Loeffler et al., 2007; Ogeer-Gyles et al., 2006;

124 Perreten et al., 2010; Ruscher et al., 2009; Sanchez et al., 2002; Shaheen et al., 2010; Warren et

125 al., 2001). As a consequence, some veterinarians have started to use critically-important

126 antimicrobial drugs such as the carbapenems. Usage of these last-resort antimicrobials is an

127 unwanted practice in veterinary medicine due to public health concerns (Boothe, 2006). This

128 new trend in antimicrobial usage emphasizes the need for alternative treatment options and

129 nitrofurantoin represents an ideal alternative to carbapenems in the treatment of canine or feline

130 UTI associated with multidrug-resistant bacteria. The clinical efficacy of nitrofurantoin has been

131 recently documented in a case of lower UTI caused by MRSP and Enterococcus faecalis in a cat

132 with pre-existing and recurrent urethral obstruction (Pomba et al., 2010).

134 The MPC values were $128 \mu \mathrm{g} / \mathrm{ml}$ for both E. coli strains and $64 \mu \mathrm{g} / \mathrm{ml}$ for both $S$.

135 pseudintermedius strains. The MIC was recorded for all presumptive mutants isolated from MPC

136 plates and only one E. coli strain had a higher MIC (128 $\mu \mathrm{g} / \mathrm{ml})$ compared with the respective

137 wild type strain $(16 \mu \mathrm{g} / \mathrm{ml})$. The clinical relevance of the MPC data is uncertain since the

138 apparent bacterial growth on MPC plates containing drug concentrations above MIC was not due

139 to the emergence of a subpopulation of resistant mutants but appeared to be an artefact

140 determined by the high density of the inoculum. Resistance to nitrofurantoin in E. coli is known

141 to occur as a result of step-wise mutations (Breeze and Obaseiki-Ebor, 1983; Sandegren et al.,

142 2008). Assuming that the drug concentrations achievable in canine urine during therapy 
143 approximate 60 to $100 \mu \mathrm{g} / \mathrm{ml}$ depending on the specific formulation (Conklin et al., 1969),

144 nitrofurantoin would not be effective against mutants with high MICs such as that obtained from

145 the MPC test in this study (MIC=128 $\mu \mathrm{g} / \mathrm{ml}$ ). However, it has been shown that the growth rate of

146 first-step mutants is impaired at concentrations well below $100 \mu \mathrm{g} / \mathrm{ml}$, and that second-step

147 mutants have an impaired growth rate at $100 \mu \mathrm{g} / \mathrm{ml}$ (Sandegren et al., 2008). Based on these

148 data, emergence of resistant mutants during therapy does not seem to be a critical issue in the 149 treatment of UTI with nitrofurantoin. It should be noted that after many years of use in human

150 medicine, nitrofurantoin resistance is still uncommon in E. coli isolated from human UTI (Garau,

151 2008; Kashanian et al., 2008; Schito et al., 2009; Zhanel et al., 2005).

152 In conclusion, the use of nitrofurantoin for treatment of UTI in dogs is a matter of weighing the

153 risks of toxicity against the benefits of clinical efficacy. Due to its high toxicity and poor

154 pharmacokinetic performance, nitrofurantoin is not a suitable first-line agent for empirical 155 treatment of UTI in small animals. However, the results of this study indicate that the use of 156 nitrofurantoin may be indicated for treatment of UTI caused by MDR E. coli or MRSP, which 157 are otherwise difficult to treat using conventional veterinary antimicrobial products. Standard 158 dosage regimens seem sufficient to kill susceptible strains and probably also prevent selection of 159 resistant mutants during therapy. The MIC distribution data generated by this study may be used 160 for setting species-specific epidemiological cut-off values and clinical breakpoints for

161 nitrofurantoin susceptibility testing in UTI isolates from dogs and cats. Setting of UTI-specific

162 clinical breakpoints will require additional data on the PK/PD properties of nitrofurantoin in

163 these animal species and clinical outcome data from perspective clinical studies. 
167 Ball, K.R., Rubin, J.E., Chirino-Trejo, M., Dowling, P.M., 2008. Antimicrobial resistance and 168 prevalence of canine uropathogens at the Western College of Veterinary Medicine Veterinary 169 Teaching Hospital, 2002-2007. Can. Vet. J. 49, 985-990.

170 Blondeau, J.M., 2009. New concepts in antimicrobial susceptibility testing: the mutant 171 prevention concentration and mutant selection window approach. Vet. Dermatol. 20, 383-396.

172 Boothe, D.M., 2006. Principles of antimicrobial therapy. Vet. Clin. North Am. Small Anim.

173 Pract. 36, 1003-1047.

174 Breeze, A.S., Obaseiki-Ebor, E.E., 1983. Mutations to nitrofurantoin and nitrofurazone 175 resistance in Escherichia coli K12. J. Gen. Microbiol. 129, 99-103.

176 Carattoli, A., Lovari, S., Franco, A., Cordaro, G., Di Matteo, P., Battisti, A., 2005. Extended177 spectrum beta-lactamases in Escherichia coli isolated from dogs and cats in Rome, Italy, from 1782001 to 2003. Antimicrob. Agents Chemother. 49, 833-835.

179 Clinical and Laboratory Standards Institute (CLSI). 2008. Performance standards for 180 antimicrobial disk and dilution susceptibility tests for bacteria isolated from animals. Approved 181 Standard - Third Edition M31-A3. Clinical and Laboratory Standards Institute, Wayne, PA.

182 Clinical and Laboratory Standards Institute (CLSI). 2010. Performance standards for 183 antimicrobial susceptibility testing; Twentieth informational supplement. Approved Standard 184 M100-S20. Clinical and Laboratory Standards Institute, Wayne, PA. 
185 Conklin, J.D., Sobers, R.J., Wagner, D.L., 1969. Urinary drug excretion in dogs during

186 therapeutic doses of different nitrofurantoin dosage forms. J. Pharm. Sci. 58, 1365-1368.

187 El Zubeir, I.E.M., Kanbar, T., Alber, J., Lammler, C., Akineden, O., Weiss, R., Zschock, M.,

188 2007. Phenotypic and genotypic characteristics of methicillin/oxacillin-resistant Staphylococcus

189 intermedius isolated from clinical specimens during routine veterinary microbiological

190 examinations. Vet. Microbiol. 121, 170-176.

191 Garau, J., 2008. Other antimicrobials of interest in the era of extended-spectrum beta-lactamases:

192 fosfomycin, nitrofurantoin and tigecycline. Clin. Microbiol. Infect. 14, 198-202.

193 Hansen, G.T., Blondeau, J.M., 2005. Comparison of the minimum inhibitory, mutant prevention

194 and minimum bactericidal concentrations of ciprofloxacin, levofloxacin and garenoxacin against

195 enteric Gram-negative urinary tract infection pathogens. J. Chemother. 17, 484-492.

196 Hooper, D.C., 2010. Urinary Tract Agents: Nitrofurantoin and Methenamine. In: Mandell, G.L.,

197 Bennet J.E., Dolin R. (Eds.), Principles and Practice of Infectious Diseases, Elsevier,

198 Philadelphia.

199 Kadlec, K., Schwarz, S., Perreten, V., Andersson, U.G., Finn, M., Greko, C., Moodley, A.,

200 Kania, S.A., Frank, L.A., Bemis, D.A., Franco, A., Iurescia, M., Battisti, A., Duim,

201 B., Wagenaar, J.A., van Duijkeren, E., Weese, J.S., Fitzgerald, J.R., Rossano, A., Guardabassi,

202 L., 2010. Molecular analysis of methicillin-resistant Staphylococcus pseudintermedius of feline

203 origin from different European countries and North America. J. Antimicrob. Chemother. 65, $204 \quad 1826-1828$. 
205 Kashanian, J., Hakimian, P., Blute, M., Wong, J., Khanna, H., Wise, G., Shabsigh, R., 2008.

206 Nitrofurantoin: the return of an old friend in the wake of growing resistance. Br. J. Urol. Int. 102, 207 1634-1637.

208 Ling, G.V., Norris, C.R., Franti, C.E., Eisele, P.H., Johnson, D.L., Ruby, A.L., Jang, S.S., 2001. 209 Interrelations of organism prevalence, specimen collection method, and host age, sex, and breed 210 among 8,354 canine urinary tract infections (1969-1995). J. Vet. Intern. Med. 15, 341-347.

211 Loeffler, A., Linek, M., Moodley, A., Guardabassi, L., Sung, J.M.L., Winkler, M., Weiss, R., 212 Lloyd, D.H., 2007. First report of multiresistant, mecA-positive Staphylococcus intermedius in 213 Europe: 12 cases from a veterinary dermatology referral clinic in Germany. Vet. Dermatol. 18, $214 \quad 412-421$.

215 Niazi, S., Vishnupad, K.S., Vengpedersen, P., 1983. Absorption and disposition characteristics of 216 nitrofurantoin in dogs. Biopharmaceut. Drug Disp. 4, 213-223.

217 Ogeer-Gyles, J., Mathews, K., Weese, J.S., Prescott, J.F., Boerlin, P., 2006. Evaluation of 218 catheter-associated urinary tract infections and multi-drug-resistant Escherichia coli isolates 219 from the urine of dogs with indwelling urinary catheters. J. Am. Vet. Med. Ass. 229, 1584-1590.

220 Perreten, V., Kadlec, K., Schwarz, S., Andersson, U.G., Finn, M., Greko, C., Moodley, A., 221 Kania, S.A., Frank, L.A., Bemis, D.A., Franco, A., Iurescia, M., Battisti, A., Duim, B., 222 Wagenaar, J.A., van Duijkeren, E., Weese, J.S., Fitzgerald, J.R., Rossano, A., Guardabassi, L., 223 2010. Clonal spread of methicillin-resistant Staphylococcus pseudintermedius in Europe and 224 North America: an international multicentre study. J. Antimicrob. Chemother. 65, 1145-1154. 
225 Pomba, C., Couto, N., Moodley, A., 2010. Treatment of a lower urinary tract infection in a cat

226 caused by a multi-drug methicillin-resistant Staphylococcus pseudintermedius and Enterococcus

227 faecalis. J. Fel. Med. Surg. 12, 802-806.

228 Rohrich, P.J., Ling, G.V., Ruby, A.L., Jang, S.S., Johnson, D.L., 1983. In vitro susceptibilities of

229 canine urinary bacteria to selected antimicrobial agents. J. Am. Vet. Med. Assoc. 183, 863-867.

230 Ruscher, C., Lubke-Becker, A., Wleklinski, C.G., Soba, A., Wieler, L.H., Walther, B., 2009.

231 Prevalence of Methicillin-resistant Staphylococcus pseudintermedius isolated from clinical

232 samples of companion animals and equidaes. Vet. Microbiol. 136, 197-201.

233 Sanchez, S., Stevenson, M.A.M., Hudson, C.R., Maier, M., Buffington, T., Dam, Q., Maurer, 234 J.J., 2002. Characterization of multidrug-resistant Escherichia coli isolates associated with 235 nosocomial infections in dogs. J. Clin. Microbiol. 40, 3586-3595.

236 Sandegren, L., Lindqvist, A., Kahlmeter, G., Andersson, D.I., 2008. Nitrofurantoin resistance 237 mechanism and fitness cost in Escherichia coli. J. Antimicrob. Chemother. 62, 495-503.

238 Schito, G.C., Naber, K.G., Botto, H., Palou, J., Mazzei, T., Gualco, L., Marchese, A., 2009. The 239 ARESC study: an international survey on the antimicrobial resistance of pathogens involved in 240 uncomplicated urinary tract infections. Int. J. Antimicrob. Agents 34, 407-413.

241 Shaheen, B.W., Boothe, D.M., Oyarzabal, O.A., Smaha, T., 2010. Antimicrobial resistance 242 profiles and clonal relatedness of canine and feline Escherichia coli pathogens expressing 243 multidrug resistance in the United States. J. Vet. Intern. Med. 24, 323-330. 
244 Warren, A.L., Townsend, K.M., King, T., Moss, S., O'Boyle, D., Yates, R.M., Trott, D.J., 2001.

245 Multi-drug resistant Escherichia coli with extended-spectrum beta-lactamase activity and

246 fluoroquinolone resistance isolated from clinical infections in dogs. Aust. Vet. J. 79, 621-623.

247 Zhanel, G.G., Hisanaga, T.L., Laing, N.M., DeCorby, M.R., Nichol, K.A., Palatnick, L.P.,

248 Johnson, J., Noreddin, A., Harding, G.K.M., Nicolle, L.E., Hoban, D.J., 2005. Antibiotic

249 resistance in outpatient urinary isolates: final results from the North American Urinary Tract

250 Infection Collaborative Alliance (NAUTICA). Int. J. Antimicrob. Agents 26, 380-388.

251 
251 Table 1. Nitrofurantoin minimum inhibitory concentrations (MIC) in Escherichia coli and

252 Staphylococcus pseudintermedius isolates from small animals.

\begin{tabular}{|c|c|c|c|c|c|c|c|c|}
\hline \multirow[t]{2}{*}{ Species } & \multirow{2}{*}{$\begin{array}{l}\text { No. } \\
\text { isolates }\end{array}$} & \multicolumn{7}{|c|}{$\mathrm{MIC}(\mu \mathrm{g} / \mathrm{ml})$} \\
\hline & & 2 & 4 & 8 & 16 & 32 & 64 & 128 \\
\hline E. coli & 106 & $0(0 \%)$ & $0(0 \%)$ & $4(3,77 \%)$ & $90(84,91 \%)$ & $12(11,32 \%)$ & $0(0 \%)$ & $0(0 \%)$ \\
\hline$S$. & 163 & $0(0 \%)$ & $1(0,61 \%)$ & $122(74,85 \%)$ & $40(24,54 \%)$ & $0(0 \%)$ & $0(0 \%)$ & $0(0 \%)$ \\
\hline pseudin & & & & & & & & \\
\hline
\end{tabular}

253

254 